\title{
HYSTERECTOMY: CHANGING TRENDS IN A TERTIARY CARE CENTER
}

\author{
Abha Singh1, Smrity Naik², Anchala Mahilange ${ }^{3}$
}

1Professor Director and HOD, Department of Obstetrics and Gynecology, Pt. JNM Medical College and Dr. Bhimrao Ambedkar Memorial Hospital, Raipur, Chhattisgarh.

${ }^{2}$ Assistant Professor, Department of Obstetrics and Gynecology, Pt. JNM Medical College and Dr. Bhimrao Ambedkar Memorial Hospital, Raipur, Chhattisgarh.

${ }^{3}$ Senior Registrar, Department of Obstetrics and Gynecology, Pt. JNM Medical College and Dr. Bhimrao Ambedkar Memorial Hospital, Raipur, Chhattisgarh.

ABSTRACT: BACKGROUND: Hysterectomy is the most common gynec operation worldwide. It leads to significant morbidity and mortality hence there must be justifiable indication before procedure is undertaken. There is a lack of comprehensive data and too much variability from place to place, even in India.

OBJECTIVE: To analyze the changing trends in hysterectomy in past 6 years.

METHOD: A retrospective study of all women undergoing hysterectomy that were done in Dr. B.R.A.M. Hospital, Medical College, Raipur for 6yrs from 2009 to 2014.

RESULTS: A total of 1032 hysterectomies were done during the study period. Most common age group was from 41-50 years. The commonest indication was symptomatic fibroid (33.52\%). Vaginal and abdominal hysterectomy were done equally. A declining trend of incidence of hysterectomy was observed over the years from 14.9 to 9.61 per 1000 women per year, which is significant (p value- 0.008).

CONCLUSION: This study shows changing scenario of hysterectomy in terms of age, oophorectomy and rate. A shift towards minimal invasive techniques is also evident.

KEYWORDS: Hysterectomy, Trend, Rate.

HOW TO CITE THIS ARTICLE: Abha Singh, Smrity Naik, Anchala Mahilange. "Hysterectomy: Changing Trends in a Tertiary Care Center". Journal of Evolution of Medical and Dental Sciences 2015; Vol. 4, Issue 89, November 05; Page: 15407-15409, DOI: $10.14260 /$ jemds/2015/2196.

INTRODUCTION: "The past can teach us, nurture us, but it cannot sustain us. The essence of life is change and we must move forward or the soul will wither or die." The beautiful words which say that with time everything changes, nothing is static. Hysterectomy is a definite management option for a number of diseases right from benign to malignant conditions but it is not without complications. It is associated with complications like hemorrhage, injuries like ureteric, bladder and bowel, sepsis, vesico-vaginal fistula, uretero-vaginal fistula, chronic pelvic pain, sexual dysfunction, incisional hernia, premature menopause and vault prolapse. One of the larger studies done in Finland highlighted the associated complications accompanying hysterectomy and concluded that whenever possible, it should be minimally invasive. ${ }^{1}$

The short term mortality is reported to be 1-6 per 1000 women, when hysterectomy is done only for benign reasons. Women aged less than 45years had a significant long term mortality. Women with only removal of uterus had 3 times greater risk of CVD, but if ovaries are also removed the risk rises7 times. ${ }^{2}$ the long term effects include pelvic organ prolapse. ${ }^{3}$

A study conducted in Haryana, India states that incidence of hysterectomy was $7 \%$ among married women.

Financial or Other, Competing Interest: None.

Submission 10-10-2015, Peer Review 12-10-2015,

Acceptance 21-10-2015, Published 03-11-2015.

Corresponding Author:

Dr. Smrity Naik,

525, Proyadarshini Nagar,

Near Pachpedi Naka,

Raipur-492001, C. G.

E-mail: smritynaik@rediffmail.com

DOI:10.14260/jemds/2015/2196.
Another study from Gujarat pointed out that 7-8\% of rural women and $5 \%$ of urban women had already undergone hysterectomy at an average age of 37 year. ${ }^{4}$ Who can forget the eye opener article in TOI in 2010 which stated that $80 \%$ of rural women were hysterectomized in Andhra Pradesh. The high rates in India are because of mindset that after childbearing the uterus must be removed for the fear of malignancy. Other reasons are lack of availability of alternative treatment or an inadequate workup. Some workers have evaluated the appropriateness for benign conditions and found that $76 \%$ did not meet ACOG criteria for hysterectomy. However no such audit has been conducted in India. This study was conducted with a view to analyze the changing scenario of hysterectomy in our institute.

MATERIAL \& METHOD: The present study is an observational study on hysterectomy. It was conducted in Department of Obstetrics \& Gynecology and associated Dr. B.R.A.M. hospital, Medical College, Raipur. It is a retrospective study of all women undergoing hysterectomy that was done in Dr. B.R.A.M. Hospital Raipur for 6yrs from 2009 to 2014.

Inclusion criteria: All the women of any age who underwent hysterectomy from Jan 2009 to December 2014. Exclusion criteria: Emergency obstetric hysterectomy.

METHOD: The study was conducted retrospectively in women fulfilling inclusion criteria. The data was collected retrospectively from 1st January 2009 to 31st December 2014 from hospital medical records. Information was gathered regarding age, parity clinical features (presenting illness), menstrual history and indication of hysterectomy. Outcome was measured in terms of operative time in minutes, bladder, ureteric injury and primary hemorrhage. 
Postoperative outcome were measured in terms of immediate complications.

RESULTS: A total of 1032 hysterectomies were done during the study period. Most common age group ranged from 4150 years and maximum were done in multiparous women. The rate of hysterectomy in 31-40 years age group declined from $36.59 \%$ to $24.18 \%$ ( $p$ value 0.024 ). The commonest indication was symptomatic fibroid (33.52\%) followed by prolapse uterus $(29.74 \%)$. The age group of TAH with BSO gradually shifted from 35-44years to 45-54 years. A significant decrease in TAH with BSO was seen in 35-44 years of age group from $12.8 \%$ to $4.37 \%$ ( $\mathrm{P}$ value 0.0079 ). Out of 1032 hysterectomies 508(49.22\%) were vaginal hysterectomies while remaining $(50.78 \%)$ were done abdominally. The rate of hysterectomy in our institute fell from 14.9 to 9.61 per 1000 women per year (P value 0.008 ) during the study period. Complications were mostly associated with TAH (11.33\%) than VH (3.19\%), (P value 0.001).

DISCUSSION: The present study shows that most common age group of hysterectomy was 41-50years (Table 1), which is similar to other studies. ${ }^{5,6}$ In the age group 31-40yrs it was noted that the rate of hysterectomy fell from $36.59 \%$ (2009) to $24.18 \%$ (2014) which is significant (P value 0.024).7,8 Most of hysterectomy were done in multiparous women.8,9 Our majority of patients had undergone hysterectomy for fibroid (Table 2) as found in other parts of India. 4,9 and world wide. ${ }^{10,11,12}$ In our study, abdominal and vaginal hysterectomy were done equally. Apart from prolapsed uterus vaginal hysterectomy was done for 1620wks fibroid uterus.

TAH with BSO were done in only $21 \%$ of women. The most common age group of TAH with BSO was 45-54 years in 2014, while it was 35-44 year in 2009. Thus it declined from $12.8 \%$ to $4.37 \%$ which is significant (P value 0.0079 ). The age, route of hysterectomy and associated gynecologic conditions influences oophorectomy rate. There was a decline in the incidence of TAH with BSO from 31.4\% in 2009 to $10.37 \%$ in 2014 (fig.1). Removal of ovary at a young age leads to premature menopause and associated complications.

Over the past 6years, a shift toward minimal invasive procedure was evident. Use of Mirena was one of the reasons to prevent hysterectomy due to menorrhagia, though being a government institute, it is not provided but some women agreed to buy it. Use of LEEP and Cryotherapy to manage cervical dysplasia at an early stage prevented many women from undergoing hysterectomy. LEEP had an upper edge over cryotherapy as the histopathplogical specimen was there. ${ }^{13}$

The facility of UAE in our hospital started very recently and has been utilized in women with fibroid. It is safe and effective uterine sparing option. Though associated with complications like pain and sepsis, ${ }^{14}$ we faced none of them. The rate of hysterectomy has significantly declined in our study from 14.9 to 9.61 per 1000 women per year (Fig. 2) (p value- 0.008). In a study by Jason et al, they found a decreasing trend of hysterectomy from 2002 to 2010 by about $36.4 \% .{ }^{15}$

CONCLUSION: India is a developing country. Majority of population still resides in rural area.
There are limited resources and women usually keep tolerating their problems till late and once they go to the hospital, they demand a permanent cure by hysterectomy. This is the era of booming technology and with new advances the treatment options are gradually shifting from surgical to minimal invasive surgery to non-surgical techniques. The underutilized minimal invasive techniques must be made more available in the rural areas. Uterus must not be considered a vestigial organ after childbearing. Every effort must be made to save it. Hysterectomy must be used as a last option. The complications after surgery are hazardous both for the woman and her family which gives them unnecessary psychological and financial stress. Before taking decision of hysterectomy, the aftermath should also be discussed.

\section{REFERENCES:}

1. Tea H. I. Brummer, Jyrki Jalkanen, Jaana Fraser et al. FINHYST, a prospective study of 5279 hysterectomies: complications and their risk factors. Human reproduction 2011;26(7):1741-1751.

2. DR IA Yakasai. Complications of hysterectomy : A review. British Journal of Science October 2013;9(2):78-87.

3. Forsgren $\mathrm{C}$, Lundholm CT, Johansson AL et al. Vaginal hysterectomy and risk of pelvic organ prolapsed and stress urinary incontinence. Int. Urogynecol. J. Pelvic floor dysfunct. 23, 43-48(2012).

4. Pandey Deeksha, Sehgal Kriti, Saxena Ashish, Hebbar Shripad, Nambiar Jayaram, and Bhat Rajehwari G. An Audit of Indications, Complications, and Justification of Hysterectomies at a Teaching Hospital in India. International Journal of Reproductive Medicine Volume 2014; Article ID 2792273: 1-6. 2014; Article ID 2792273: 1-6.

5. Patel Arti J, Tank Ashish C. Changing trends of hysterectomy: An observational study. International Journal of Scientific Research. August 2013;2(8): 323-4.

6. Intisar S. Pity, Jalal A. Jalal, Bashar A. Hassawi. Hysterectomy: A Clinicopathologic Study. Tikrit Medical Journal 2011;17(2): 7-16.

7. Mahasani V, Suchdeva R, Aggarwal A. Hysterectomy - Which approach? Peoples's Journal of Scientific Research Jan 2014;7(1):17-21.

8. R Lykke, J Blaaker, B Ottesen, H Gimbel. Hysterectomy in Denmark 1977-2011: changes in rate, indications and hospitalization. European Journal of obstetrics and Gynecology and Reproductive Biology 2013;171:333-338.

9. Bala R, Devi KP, Singh CM. Trend of Hysterectomy: A Retrospective analysis in Regional Institute of Medical Sciences (RIMS). J Med Soc 2015;29:4-7

10. Ahmed, Z.D., Taiwo, N. Indications and outcome of gynaecological hysterectomy at Aminu Kano teaching hospital, Kano: A 5 year review. Open Journal of obstetrics and gynecology 2015;5:298-304.

11. Amin A, Ali A, Amin Z, Sani FN. Justification for hysterectomies and frequency of histopathological lesions of hysterectomy at a Teaching Hospital in Peshawar, Pakistan. Pak J Med Sci 2013; 29(1):170-172.

12. Saha R, Shrestha NS, Thapa M, Shrestha J, Bajracharya J, Padhye SM. Non descent vaginal hysterectomy : Safety and Feasibility. NJOG Jul-Dec 2012;7(2):14-16. 
13. Singh A., Arthur B., Agarwal V. LEEP versus cryotherapy in CIN. The Journal of Obstetrics and Gynecology of India July-August 2011;61(4):431-435.

14. Memtsa Maria, Homer Hayden. Complications associated with uterine artery embolisation for fibroids. Obstetrics and gynecology International. 5 pages.

doi:10.1155/2012/290542.
15. Wright D. Janson, Thomas J. Herzog, Jennifer Tsui, Cande V. Ananth. Nationawide trends in the performance of inpatient hysterectomy in united states. Obstet Gynecol 2013 August;122 (2 0 1): 233- 241.

\begin{tabular}{|c|c|c|c|c|c|c|}
\hline Year & $<\mathbf{2 0}$ & $\mathbf{2 1 - 3 0}$ & $\mathbf{3 1 - 4 0}$ & $\mathbf{4 1 - 5 0}$ & $\mathbf{5 1 - 6 0}$ & $>\mathbf{6 1}$ \\
\hline 2009 & 0 & $6(3.09 \%)$ & $71(36.59 \%)$ & $81(41.75 \%)$ & $24(12.3 \%)$ & $12(6.18 \%)$ \\
\hline 2010 & 0 & $4(1.93 \%)$ & $77(37.19 \%)$ & $94(45.41 \%)$ & $22(10.6 \%)$ & $10(6.14 \%)$ \\
\hline 2011 & 0 & $5(2.79 \%)$ & $81(45.25 \%)$ & $64(35.75 \%)$ & $18(10.05 \%)$ & $11(6.14 \%)$ \\
\hline 2012 & 1 & $5(3.33 \%)$ & $38(25.33 \%)$ & $72(48 \%)$ & $27(18 \%)$ & $7(4.66 \%)$ \\
\hline 2013 & 0 & $3(1.81 \%)$ & $36(21.81 \%)$ & $88(53.33 \%)$ & $25(15.15 \%)$ & $13(7.87 \%)$ \\
\hline 2014 & 1 & $1(0.32 \%)$ & $34(24.81 \%)$ & $74(54.01 \%)$ & $16(11.6 \%)$ & $12(8.75 \%)$ \\
\hline Total & $\mathbf{7}$ & $\mathbf{2 4 ( 3 . 3 2 \% )}$ & $\mathbf{3 3 7}(\mathbf{3 2 . 6 5 \% )}$ & $\mathbf{4 7 3 ( 4 5 . 8 3 \% )}$ & $\mathbf{1 3 2 ( 1 2 . 7 9 \% )}$ & $\mathbf{6 5 ( 6 . 2 9 \% )}$ \\
\hline \multicolumn{7}{|c|}{ Table 1: Age group and Hysterectomy } \\
\hline
\end{tabular}

\begin{tabular}{|c|c|c|c|c|c|c|c|}
\hline Indication & $\begin{array}{c}2009 \\
\text { No (\%age) }\end{array}$ & $\begin{array}{c}2010 \\
\text { No (\%age) }\end{array}$ & $\begin{array}{c}2011 \\
\text { No (\%age) }\end{array}$ & $\begin{array}{c}2012 \\
\text { No (\%age) }\end{array}$ & $\begin{array}{c}2013 \\
\text { No (\%age) }\end{array}$ & $\begin{array}{c}2014 \\
\text { No (\%age) }\end{array}$ & $\begin{array}{c}\text { Total } \\
\text { No (\%age) }\end{array}$ \\
\hline Prolapse uterus & $57(29.38 \%)$ & $49(23.67 \%)$ & $48(26.81 \%)$ & $57(38 \%)$ & $56(33.93 \%)$ & $40(29.19 \%)$ & $307(29.74 \%)$ \\
\hline Fibroid uterus & $65(33.50 \%)$ & $59(28.50 \%)$ & $61(34.07 \%)$ & $57(38 \%)$ & $53(32.12 \%)$ & $51(37.22 \%)$ & $346(33.52 \%)$ \\
\hline DUB & $6(3.09 \%)$ & $25(12.07 \%)$ & $20(11.17 \%)$ & $6(4 \%)$ & $12(7.27 \%)$ & $15(10.94 \%)$ & $84(8.13 \%)$ \\
\hline Adenomyosis & $14(7.21 \%)$ & $10(4.7 \%)$ & $8(4.46 \%)$ & $9(6 \%)$ & $2(1.21 \%)$ & $8(5.83 \%)$ & $51(4.94 \%)$ \\
\hline Ca Endometrium & n $\quad 4(2.06 \%)$ & $9(4.34 \%)$ & $5(2.79 \%)$ & $2(1.33 \%)$ & $10(6.06 \%)$ & $3(2.18 \%)$ & $33(3.19 \%)$ \\
\hline Endometrial & $6(3.09 \%)$ & $15(7.24 \%)$ & $6(3.35 \%)$ & $1(0.66 \%)$ & $2(1.21 \%)$ & $3(2.18 \%)$ & $33(3.19 \%)$ \\
\hline \multicolumn{8}{|l|}{ Hyperplasia } \\
\hline CIN 3 & $8(4.12 \%)$ & $11(5.31 \%)$ & $8(4.46 \%)$ & $3(2 \%)$ & $6(3.63 \%)$ & $7(5.10 \%)$ & $43(4.16 \%)$ \\
\hline $\mathrm{CaCx}$ & $7(3.6 \%)$ & 0 & $3(1.67 \%)$ & $9(6 \%)$ & $12(7.27 \%)$ & $5(3.64 \%)$ & $36(3.48 \%)$ \\
\hline Benign ovarian & $17(8.76 \%)$ & $18(8.69 \%)$ & $8(4.46 \%)$ & $4(2.66 \%)$ & $7(4.24 \%)$ & $4(2.91 \%)$ & $58(5.62 \%)$ \\
\hline \multicolumn{8}{|l|}{ disease } \\
\hline Ca ovary & $8(4.12 \%)$ & $7(3.38 \%)$ & $5(2.79 \%)$ & $2(1.33 \%)$ & $5(3.03 \%)$ & $1(0.72 \%)$ & $28(2.71 \%)$ \\
\hline Chronic PID & $2(1.03 \%)$ & $4(1.93 \%)$ & $7(3.91 \%)$ & 0 & 0 & 0 & $13(1.25 \%)$ \\
\hline
\end{tabular}

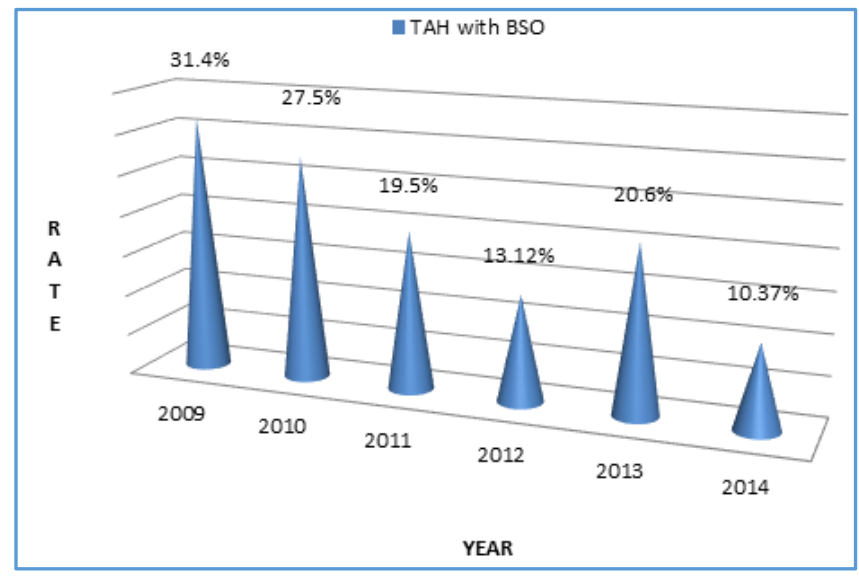

Fig. 1: Rate of TAH with BSO

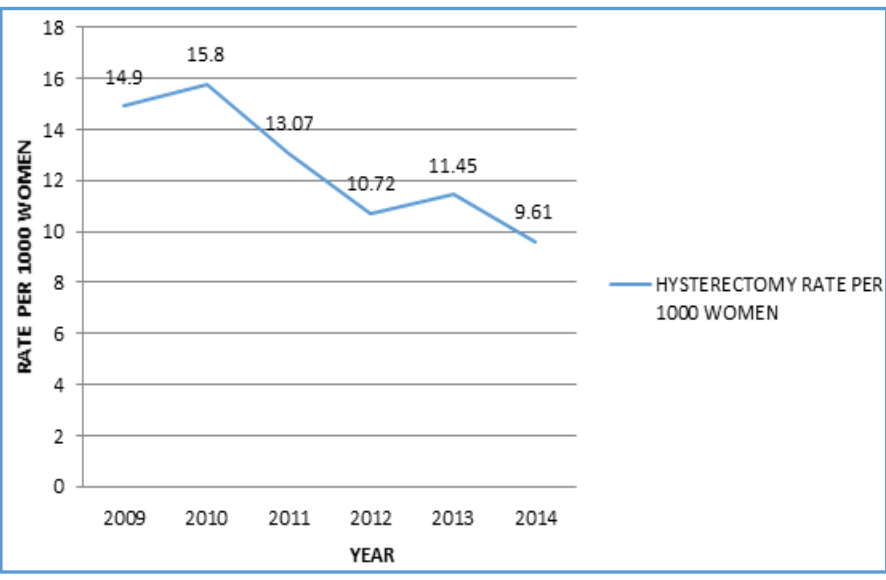

Fig. 2: Hysterectomy Rate per 1000 women 